\title{
Healthy migrants but unhealthy offspring? A retrospective cohort study among Italians in Switzerland
}

\author{
Silvan Tarnutzer, Matthias Bopp ${ }^{*}$ for the SNC study group
}

\begin{abstract}
Background: In many countries, migrants from Italy form a substantial, well-defined group with distinct lifestyle and dietary habits. There is, however, hardly any information about all-cause mortality patterns among Italian migrants and their offspring. In this paper, we compare Italian migrants, their offspring and Swiss nationals.

Methods: We compared age-specific and age-standardized mortality rates and hazard ratios (adjusted for education, marital status, language region and period) for Swiss and Italian nationals registered in the Swiss National Cohort (SNC), living in the German- or French-speaking part of Switzerland and falling into the age range 40-89 during the observation period 1990-2008. Overall, 3,175,288 native Swiss (48\% male) and 224,372 individuals with an Italian migration background (57\% male) accumulated 698,779 deaths and 44,836,189 person-years. Individuals with Italian background were categorized by nationality, country of birth and language.

Results: First-generation Italians had lower mortality risks than native Swiss (reference group), but second-generation Italians demonstrated higher mortality risks. Among first-generation Italians, predominantly Italian-speaking men and women had hazard ratios (HRs) of 0.89 (95\% Cl: 0.88-0.91) and 0.90 (0.87-0.92), respectively, while men and women having adopted the regional language had HRs of 0.93 (0.88-0.98) and 0.96 (0.88-1.04), respectively. Among second-generation Italians, the respective HRs were 1.16 (1.03-1.31), 1.06 (0.89-1.26), 1.10 (1.05-1.16) and 0.97 (0.89-1.05). The mortality advantage of first-generation Italians decreased with age.

Conclusions: The mortality risks of first- and second-generation Italians vary substantially. The healthy migrant effect and health disadvantage among second-generation Italians show characteristic age/sex patterns. Future investigation of health behavior and cause-specific mortality is needed to better understand different mortality risks. Such insights will facilitate adequate prevention and health promotion efforts.
\end{abstract}

\section{Background}

Migrants to European countries (e.g., Sweden, Belgium and the Netherlands) were reported to have lower overall mortality rates than the respective local population [1-3]. A similar difference has been documented for Latino immigrants to the United States [4,5]. In Europe as well as in the U.S., migrants are generally characterized by low socio-economic status (SES) and working in unhealthy jobs. Low SES has been shown to be related to unfavorable health behavior, opportunities and outcomes (e.g., physical inactivity, smoking, unhealthy dietary habits, difficulties in accessing health services, morbidity and mortality) [6-8].

\footnotetext{
* Correspondence: bopp@ifspm.uzh.ch

Institute of Social and Preventive Medicine, University of Zurich, Hirschengraben 84, 8001, Zurich, Switzerland
}

This phenomenon of lower mortality in the socioeconomically disadvantaged Latino population in the U.S. was called the "Latino mortality paradox" [9]. This term was later modified in the European context to "Mediterranean migrants' mortality paradox" [10].

Established theoretical explanations focus on selective migration flows of healthy workers (healthy-migrant hypothesis). Others assume that protective social and cultural factors from the country of origin entail general health advantages,e.g., lower suicide rates among migrants from Southern Europe [11,12]. Generally, the impact of the culture of origin diminishes with increasing length of stay [12]. The literature suggests that beliefs and norms concerning health behavior change due to acculturation [13]. Language is a proxy for acculturation. Furthermore,
C Biomed Central

(c) 2012 Tarnutzer and Bopp; licensee BioMed Central Ltd. This is an Open Access article distributed under the terms of the Creative Commons Attribution License (http://creativecommons.org/licenses/by/2.0), which permits unrestricted use, distribution, and reproduction in any medium, provided the original work is properly cited. 
it has repeatedly been shown that language is an important predictor of health care utilization and health status [14]. However, it has been reported that acculturation processes and SES are interlinked and should both be considered [14].

Methodical and conceptual considerations are related to the choice of the reference population (host population vs. non migrating cohort in the country of origin) and distinguish between 'arrival' and 'post-arrival' phase' [15]. Further difficulties refer to the re-migration of sick individuals (salmon-bias hypothesis) [3,9] and under-reported re-emigration ('over-coverage' [16]), bothbiasing mortality figures. However, several findings suggest that the lower mortality among migrants is at least partially real $[3,5,9,17]$. With the Swiss National Cohort (see Methods, below), we substantially reduce the over-coverage and other numerator/denominator problems occurring in mortality analyses among migrant populations.

There is abundant literature investigating cancer among Italian migrants, e.g. [18]. However, to our knowledge systematic analyses on all-cause mortality are lacking. This paper presents differences in all-cause mortality between Swiss nationals and individuals with an Italian background. Italians were the most numerous foreign population group in Switzerland since World War II, reaching a maximum of 555,000 persons in 1974 (seasonal workers not included) - i.e., $52 \%$ of all foreign nationals or almost $9 \%$ of the overall population of Switzerland at that time [19].

In Switzerland, health care insurance is mandatory, and access to health care is regarded to be universal [20]. However, while lower overall hospitalization rates were reported for migrants generally, Italians had higher rates for admissions due to ischemic heart diseases [21]. Self-reported health of immigrants has also been lower than that of Swiss nationals [22].

In our analyses, we investigate the hypotheses that compared to native Swiss (1) Italian immigrants possess an all-cause mortality advantage whereas (2) their offspring demonstrate higher all-cause mortality risk, but differences in mortality are (3) moderated by the adoption of Swiss regional languages.

\section{Methods}

\section{Data}

Data were derived from the Swiss National Cohort (SNC), an anonymous record linkage of census, cause of death and emigration files [23]. Ethics approval (Nr. 13/ 06) was obtained by the Ethics Committee of the Canton of Zurich (Kantonale Ethik-Kommision, KEK).

Between 1850 and 2000, national censuses were conducted in Switzerland at 10-year intervals in early December of a census year and information about sex, age, country of birth, nationality, educational level and marital status is taken from the 1990 census. Marital status was categorized into single, married, widowed and divorced/ separated. Educational level was classified according to the International Standard Classification of Education (ISCED): compulsory schooling (ISCED levels 0-2), secondary (3), higher secondary (4) and tertiary education (5-6) [24]. Usual minimal numbers of years for each educational category in Switzerland are 9, 11-12, 14-15 and 16, respectively. Swiss census enumeration and registration of deaths occurring in Switzerland (including cause of death information) is presumed to be virtually complete [25].

In multilingual persons, the preferred language is also a significant marker of cultural identity. A special feature of Swiss censuses is the assessment of mastered languages. Until 1980, censuses included only one language item ("What language do you think in and do you master best?"), permitting only a single response. Although in 1990 this question was complemented by additional language questions, the quality of these items is unsure. Hence we restricted the analyses to the more reliable question concerning principal language. One out of four Italians born in Switzerland still reported Italian as their main language. Nevertheless, it can be assumed that the vast majority of individuals with Italian background can understand both Italian and the regional language, and that the principal language indicated stands more for mental acculturation than actual fluency.

For comparisons with the non-migrating cohort in the country of origin, cross-sectional mortality and population data for Italy was derived from the WHO mortality database (http://www.who.int/whosis/mort/download/en/).

\section{Migration background}

In this study, migration background is conceptualized by considering both citizenship (addressed as nationality below) and birthplace. In Swiss law, citizenship is acquired through descent (jus sanguinis) or naturalization (after a relatively long stay in the country and sufficient knowledge of regional language).

Migration status was categorized into four groups:

1) First-generation Italians (in analyses referred to as "IT, "IT"): Italian nationality, born in Italy

2) Second-generation Italians (IT, " $\mathrm{CH}$ ): Italian nationality, born in Switzerland

3) Italy-born Swiss (CH, "IT): Swiss nationality, born in Italy

4) Native Swiss $\left(\mathrm{CH},{ }^{*} \mathrm{CH}\right)$ : Swiss nationality, born in Switzerland

The category "Italy-born Swiss" encompasses both naturalized Italian immigrants and native Swiss born in Italy. In the 1990 census, only one nationality could be 
reported. Swiss nationals with additional citizenship were instructed to declare themselves as "Swiss". Therefore, we have no information on individuals' possible second nationalities. For multivariate analyses, we further differentiated people with Italian background into those who reported Italian as principal language and those reporting the region-specific language (German or French).

\section{Inclusion/exclusion criteria}

The current SNC database encompasses 6,873,687 persons registered in the 1990 census and 1,037,335 deaths occurring between the 1990 census and the end of 2008 . Individuals with non-Swiss and non-Italian nationality or born in neither Switzerland nor Italy were excluded. We further excluded persons living in the Italian-speaking part of Switzerland ( 4\%) or reporting a language other than Italian or the regional Swiss language. Cut-off points for age at baseline were set at 25 and 90 years. However, individuals contributed person years and deaths only after their 40th birthday. The high lower age limit is due to the reliance on educational data from the 1990 census, implying that generally even the youngest individuals included in our analyses should have reached their highest educational level by 1990 . We further excluded 186,732 individuals which could neither be linked to a 2000 census record nor were documented to have died or emigrated.

Each individual added person-years starting at the 40th birthday and ending either one day before the 90th birthday, date of death or emigration or December 31, 2008. With respect to all mentioned conditions, $3,399,660$ individuals accumulating 698,779 deaths and $44,836,189$ person years were included.

Observation time was partitioned into two periods. The first one begins on the day of the 1990 census (December 4, 1990) and ends on the 2000 census day (December 5, 2000). Within this time-span, follow-up status of the whole study population is known. The second period starts at December 5, 2000 and ends on December 31, 2008 and contains an unknown number of individuals lost to follow-up (all persons without

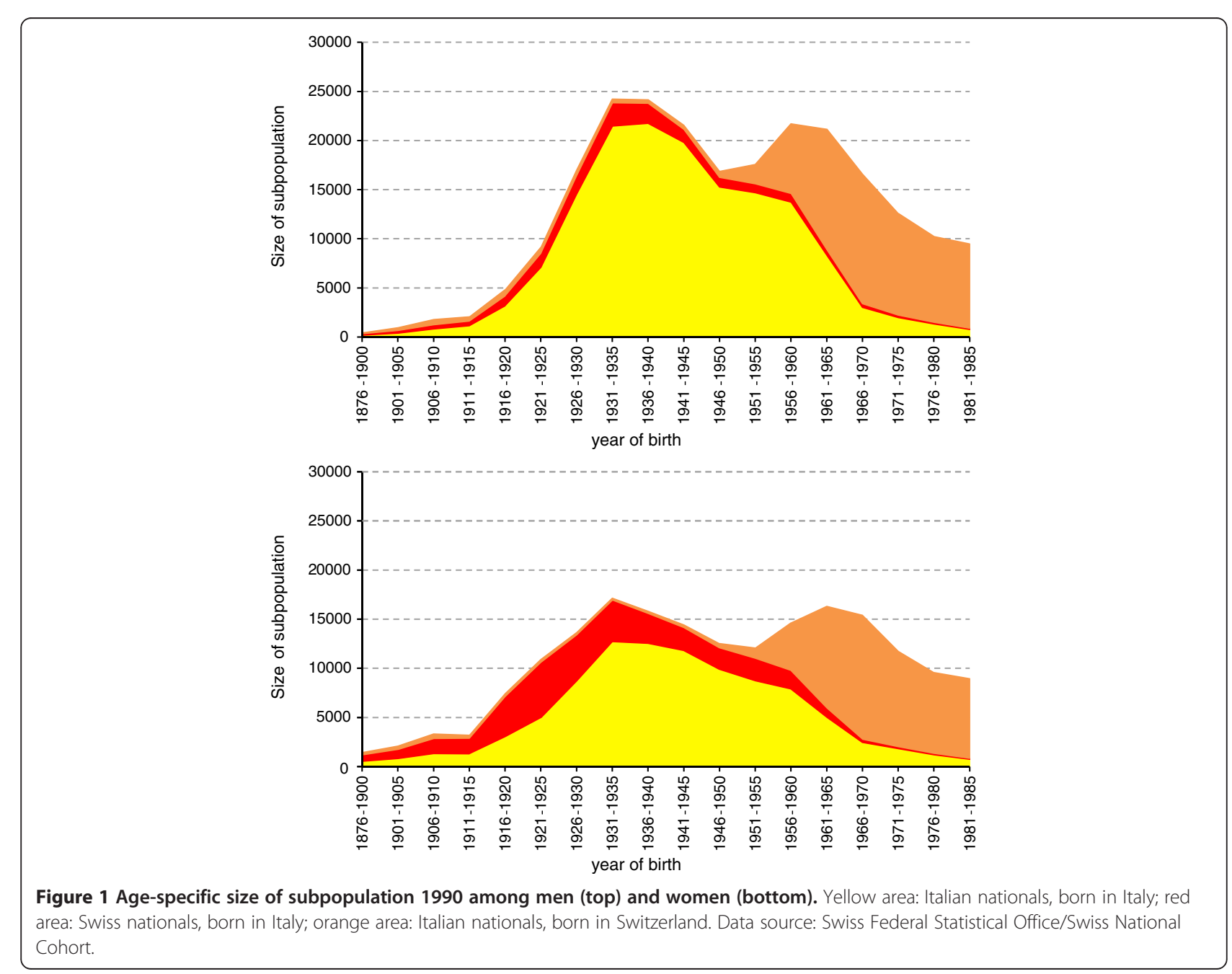


linked death or emigration record have to be assumed to be alive at the end of 2008).

\section{Procedures}

Statistical analyses were done in Stata 11.2 [26] and cover descriptive statistics (counts, means and relative frequencies), age-standardized (WHO standard population "Europe") mortality rates and multivariate models (Cox regressions). The proportional hazard assumption appeared to be widely fulfilled.

\section{Results}

\section{Descriptive analyses}

In 1990 and depending on age class, male and female Italian nationals made up to $11 \%$ and $7 \%$, respectively, of Switzerland's population (Figure 1). Furthermore, secondgeneration Italians accounted for up to $6 \%$ of the population in the birth cohorts 1966-1990.

Among Italian nationals - irrespective of place of birth - men outnumbered women slightly, whereas almost three out of four Italy-born Swiss nationals were women (Table 1). Generally, educational achievement was higher in Swiss than in Italian nationals and in men than in women. Among both men and women, Swiss nationals born in Italy had the highest proportion of tertiary education. Variation in marital status between the four migration categories broadly reflects differences in age structure.
For men and women, proportions of Italian nationals were higher in French- than in German-speaking Switzerland.

\section{Age-standardized mortality rates}

In general, age-standardized mortality rates were lower in first-generation Italians than native Swiss (Table 2). However, the difference was only significant among women. In contrast, second-generation migrants had higher mortality rates than native Swiss. Finally, Italyborn Swiss demonstrated lower mortality than native Swiss.

For an evaluation of variation by age, we compared age-specific rates (averaged over the years 1991-2000) with information from the WHO Mortality Database for Italy. The comparison showed nearly identical rates for Italy's population and native Swiss nationals - only Swiss aged over 60 years had a mortality advantage (Figure 2). The healthy migrant effect of first-generation Italian migrants was clearly observable for men younger than 60 years and women younger than 50 years. Secondgeneration Italians aged less than 45 years had lower and those aged between 45 and 70 years had higher mortality compared to Italy's population as well as native Swiss.

\section{Multivariate analyses}

Among men, Cox regressions with the explanatory variables migration group (including best mastered language),

Table 1 Study population, Swiss National Cohort, 1990-2008, 25-89 years at baseline

\begin{tabular}{|c|c|c|c|c|c|c|c|c|c|c|}
\hline & & \multicolumn{4}{|l|}{ Men } & \multicolumn{4}{|l|}{ Women } & \multirow[b]{2}{*}{ Tota } \\
\hline & & IT, *IT & $\mathrm{IT}, * \mathrm{CH}$ & $\mathrm{CH}, * \mathrm{IT}$ & $\mathrm{CH},{ }^{*} \mathrm{CH}$ & IT, *IT & $\mathrm{IT}, * \mathrm{CH}$ & $\mathrm{CH}, * \mathrm{IT}$ & $\mathrm{CH},{ }^{*} \mathrm{CH}$ & \\
\hline \multirow[t]{3}{*}{$\begin{array}{l}\text { Individuals included } \\
\text { in analysis }\end{array}$} & $\begin{array}{l}\text { German-speaking } \\
\text { Switzerland }\end{array}$ & 74,528 & 8,315 & 5,250 & $1,192,789$ & 46,231 & 5,482 & 14,110 & $1,293,754$ & $2,640,459$ \\
\hline & French-speaking Switzerland & 32,068 & 3,807 & 2,983 & 323,026 & 20,529 & 2,400 & 8,669 & 365,719 & 759,201 \\
\hline & $\begin{array}{l}\text { German-+ French-speaking } \\
\text { Switzerland }\end{array}$ & 106,596 & 12,122 & 8,233 & $1,515,815$ & 66,760 & 7,882 & 22,779 & $1,659,473$ & $3,399,660$ \\
\hline \multirow[t]{2}{*}{ Person-years } & $1990-2000$ & 748,976 & 34,473 & 68,081 & $10,631,070$ & 480,393 & 19,316 & 190,449 & $11,935,429$ & $24,108,187$ \\
\hline & $2000-2008$ & 589,674 & 64,436 & 51,598 & $9,200,327$ & 383,932 & 41,987 & 146,106 & $10,249,943$ & $20,728,002$ \\
\hline \multirow[t]{2}{*}{ Deaths } & 1990-2000 & 6,241 & 1,166 & 1,132 & 213,898 & 2,658 & 414 & 2,480 & 180,515 & 408,504 \\
\hline & $2000-2008$ & 6,323 & 607 & 885 & 148,670 & 2,746 & 252 & 2,286 & 128,506 & 290,275 \\
\hline \multicolumn{2}{|l|}{ Mean age on $1990,12,4$} & 46.0 & 38.2 & 53.0 & 49.4 & 47.0 & 36.5 & 55.9 & 51.4 & 50.2 \\
\hline \multirow[t]{4}{*}{ Education (\%) } & Compulsory schooling & 59.1 & 21.4 & 26.9 & 19.6 & 81.7 & 33.7 & 62.4 & 39.5 & 32.2 \\
\hline & Secondary & 35.5 & 64.7 & 49.8 & 57.7 & 16.8 & 62.4 & 32.6 & 54.5 & 54.5 \\
\hline & Upper Secondary & 3.9 & 11.0 & 13.2 & 15.1 & 0.8 & 2.8 & 2.4 & 3.9 & 8.9 \\
\hline & Tertiary & 1.4 & 3.0 & 10.2 & 7.5 & 0.7 & 1.1 & 2.6 & 2.1 & 4.5 \\
\hline \multirow[t]{4}{*}{ Marital status (\%) } & Single & 11.1 & 41.6 & 8.1 & 19.2 & 7.7 & 41.8 & 3.4 & 15.8 & 17.1 \\
\hline & Married & 83.4 & 51.5 & 83.4 & 72.2 & 81.9 & 50.1 & 71.6 & 63.0 & 68.1 \\
\hline & Widowed & 1.3 & 2.5 & 3.1 & 3.5 & 7.1 & 4.6 & 16.9 & 14.5 & 9.0 \\
\hline & Separated/divorced & 4.3 & 4.5 & 5.5 & 5.1 & 3.4 & 3.5 & 8.2 & 6.7 & 5.9 \\
\hline \multirow[t]{2}{*}{ Main language (\%) } & Italian & 88.6 & 23.1 & 43.7 & 3.1 & 91.3 & 28.4 & 49.2 & 3.8 & 8.4 \\
\hline & $\begin{array}{l}\text { Preponderant regional } \\
\text { language }\end{array}$ & 11.4 & 77.0 & 56.4 & 96.9 & 8.7 & 71.6 & 50.8 & 96.2 & 91.6 \\
\hline
\end{tabular}

Data source: Swiss Federal Statistical Office/Swiss National Cohort. 
Table 2 Age-standardized mortality rates per 100,000 person-years, 1990-2008 individuals aged 25-89 years at baseline

\begin{tabular}{|c|c|c|c|c|c|c|}
\hline \multirow[t]{2}{*}{ Migration category } & \multirow{2}{*}{$\frac{\text { Men }}{\text { Deaths(n) }}$} & \multicolumn{2}{|l|}{ (n: $1,642,766)$} & \multirow{2}{*}{$\frac{\text { Women }}{\text { Deaths(n) }}$} & \multicolumn{2}{|l|}{ (n:1,756,894) } \\
\hline & & Mortality rates & $95 \%-\mathrm{Cl}$ & & Mortality rates & $95 \%-\mathrm{Cl}$ \\
\hline IT, * IT & 12564 & 1532 & 1493-1572 & 5403 & 820 & $796-845$ \\
\hline $\mathrm{IT},{ }^{*} \mathrm{CH}$ & 1773 & 1944 & $1843-2045$ & 666 & 1024 & 924-1124 \\
\hline $\mathrm{CH}, * \mathrm{IT}$ & 2015 & 1373 & 1310-1436 & 4765 & 847 & $820-875$ \\
\hline $\mathrm{CH},{ }^{*} \mathrm{CH}$ & 362542 & 1550 & $1545-1555$ & 308981 & 884 & $880-887$ \\
\hline
\end{tabular}

Data source: Swiss Federal Statistical Office/Swiss National Cohort.

$\mathrm{Cl}=$ confidence interval.

* = born in; example: IT, *IT: Italians born in Italy i.e. first-generation Italians.

linguistic region (German vs. French), age, marital status, educational level and a period dummy showed significantly different mortality risks for all migration categories compared to native Swiss (Table 3). The lowest risks were observed in first-generation Italian-speaking Italians (HR: 0.89; CI: 0.88-0.91). First-generation Italians who adopted the regional language also demonstrated a lower risk (HR: 0.93; CI: 0.88-0.98), as well as Italy-born Swiss (irrespective of language). In contrast, Switzerland-born Italians had increased mortality risk (Italian speakers: $\mathrm{HR}=1.16$, CI: 1.03-1.31; regional language speakers: $\mathrm{HR}=1.10$, 1.05-1.16).

In women, two migrant groups had significantly different mortality risk compared to native Swiss, but only when adhering to Italian as main language (Table 3): first-generation Italians and Italy-born Swiss had HR's of

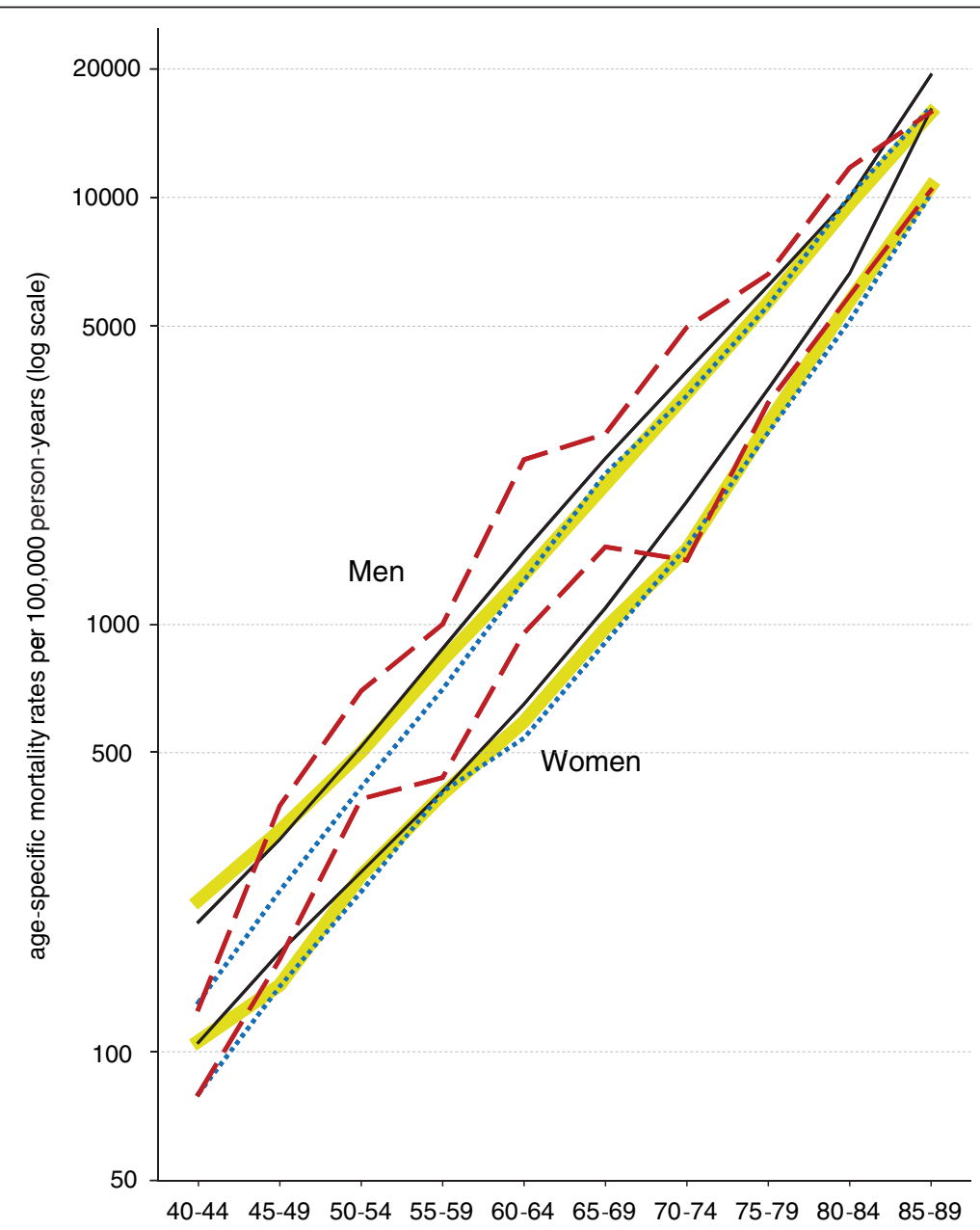

Figure 2 Age-specific mortality rates 1991-2000 among men (top) and women (bottom). Dotted blue lines: Switzerland, first-generation Italians; dashed red lines: Switzerland, second-generation Italians; yellow thick lines: native Swiss nationals; black thin lines: population of Italy. Data sources: Swiss Federal Statistical Office/Swiss National Cohort and WHO mortality database (Italy). 
Table 3 Cox regression 1990-2008, individuals aged, 25-89 years at baseline.

\begin{tabular}{|c|c|c|c|c|c|}
\hline & & Men & (n: 1,642,766) & Women & (n: 1,756,894) \\
\hline & & $\overline{\mathrm{HR}}$ & $95 \%-\mathrm{Cl}$ & $\overline{H R}$ & $95 \%-\mathrm{Cl}$ \\
\hline Age & Age & 1.02 & $1.02-1.02$ & 1.01 & $1.01-1.02$ \\
\hline \multirow[t]{7}{*}{ Migrational group } & IT, *IT, Italian & 0.89 & $0.88-0.91$ & 0.90 & $0.87-0.92$ \\
\hline & IT, *IT, Regional & 0.93 & $0.88-0.98$ & 0.96 & $0.88-1.04$ \\
\hline & $\mathrm{IT},{ }^{*} \mathrm{CH}$, Italian & 1.16 & $1.03-1.31$ & 1.06 & $0.89-1.26$ \\
\hline & $\mathrm{IT},{ }^{*} \mathrm{CH}$, Regional & 1.10 & $1.05-1.16$ & 0.97 & $0.89-1.05$ \\
\hline & $\mathrm{CH},{ }^{*} \mathrm{IT}$, Italian & 0.91 & $0.86-0.98$ & 0.94 & $0.90-0.98$ \\
\hline & $\mathrm{CH},{ }^{*} \mid \mathrm{T}$, Regional & 0.94 & $0.88-0.99$ & 0.99 & $0.95-1.03$ \\
\hline & $\mathrm{CH},{ }^{*} \mathrm{CH}$ (ref.) & 1 & & 1 & \\
\hline \multirow[t]{4}{*}{ Educational level } & Compulsory school (ref.) & 1 & & 1 & \\
\hline & Secondary education & 0.84 & $0.83-0.85$ & 0.83 & $0.83-0.84$ \\
\hline & Higher secondary education & 0.69 & $0.68-0.69$ & 0.73 & $0.71-0.75$ \\
\hline & Tertiary education & 0.59 & $0.58-0.60$ & 0.68 & $0.65-0.71$ \\
\hline \multirow[t]{4}{*}{ Marital status } & Single & 1.49 & $1.48-1.51$ & 1.29 & $1.28-1.31$ \\
\hline & Married (ref.) & 1 & & 1 & \\
\hline & Widowed & 1.18 & $1.17-1.20$ & 1.16 & $1.15-1.17$ \\
\hline & Separated/divorced & 1.55 & $1.53-1.57$ & 1.36 & $1.34-1.38$ \\
\hline \multirow[t]{2}{*}{ Language region } & German-speaking Switzerland (ref.) & 1 & & 1 & \\
\hline & French-speaking Switzerland & 1.00 & $1.00-1.01$ & 0.95 & $0.94-0.96$ \\
\hline \multirow[t]{2}{*}{ Period } & 1990-2000 (ref.) & 1 & & 1 & \\
\hline & $2000-2008$ & 0.94 & $0.92-0.95$ & 0.94 & $0.93-0.96$ \\
\hline
\end{tabular}

Data source: Swiss Federal Statistical Office/Swiss National Cohort, $\mathrm{HR}=$ hazard ratio; $\mathrm{Cl}=$ confidence interval figures in bold: significant on $5 \%$-level.

* = born in; example: $\mathrm{CH}$, *IT, Italian: Italy born Swiss who see Italian as their best mastered language.

0.90 (CI: 0.87-0.92) and 0.94 (0.90-0.98), respectively. No effect was observed for Switzerland-born Italians and for any group having adopted the regional language.

The findings also showed the higher the educational level, the lower the mortality risk. People living alone showed significantly higher mortality compared to married people. Mortality was lower in French- than German-speaking Switzerland among women, but not among men. Additional models including interaction terms between migration background and language region or period showed no remarkable differences.

\section{Discussion}

First-generation Italians had a mortality advantage compared to native Swiss. This is in line with international findings-e.g., a Swedish study on migrants from southern Europe, ex-Yugoslavia and Turkey [1] and the only Swiss study on mortality among foreigners [27] which reported lower age-standardized mortality rates for foreigners compared to Swiss nationals (men $-19 \%$, women $-14 \%$ ). However, the latter study was cross-sectional and did not distinguish between migrants and their offspring. Nevertheless, the mortality advantage of Italian immigrants in Switzerland may be a real phenomenon rather than an artifact. This notion is also supported by a Belgian study based on register data [3].
We also found that second-generation Italian men were exposed to higher mortality risk. In this group, adoption of the regional language attenuated the excess mortality observed. Other authors have also documented higher mortality rates in the offspring of migrants. In England and Wales, second- and third-generation Irish people aged 15-44 years demonstrated excess mortality $[28,29]$. Sons of Italian migrants in Sweden had a higher mortality risk than native Swedish nationals [12]. This is consistent with the acculturation hypothesis. As the duration of stay increases, immigrants increasingly adopt the local lifestyle and protective features of their culture of origin are only partially maintained by their offspring [12]. But for mortality, the acculturation hypothesis has been confirmed in some, but not all migrant populations [30-32].

In our study, the mortality advantage in first-generation Italians was greater for men than women but diminished in men and lost significance in women who had adopted the regional language.

In a study on second-generation Italians in Switzerland, two main types of orientation were differentiated: "casual Latins" emphasized their Italian origin and only rarely got involved in Switzerland's political agenda and discourses [33]. A similar observation was made for Italians living in Peterborough, UK, characterized as economically 
integrated but socially encapsulated [34]. In contrast to the "casual Latins" the "sushi-eating secondos" adhered to a cosmopolitan kind of Italian culture and lifestyle and signalized interest in cultural diversity and Swiss values [33]. It may be assumed that adoption of the regional language corresponds with these constructed ideal types. If adoption of the regional language is interpreted as an indicator of acculturation, our results are also in line with the attenuation of health advantages over time as described above.

Notwithstanding the larger proportion of people with an Italian migration background in the French-speaking part of Switzerland, separate Cox regression models could not discern clear differences in mortality risk between Italians in German- vs. French-speaking Switzerland, irrespective of adoption of the regional language.

Controlling for period revealed a period effect which may be caused by undetected loss to follow-up in the second period. Apart from this, the hazard ratios were very similar when calculated for both periods separately. The relationships between migration background and mortality may therefore be assumed to be stable over time.

\section{Strengths and limitations}

The mortality advantage of first-generation Italians in the context of our study is meaningful as we avoid the numerator-denominator bias inherent to cross-sectional studies by using SNC data. Individuals were selected if they had taken part in both Swiss censuses (1990 and 2000) or are documented to have died or emigrated. This criterion is important because many migrants who re-emigrate do not report their move to the authorities. Indeed, in Sweden, it was estimated that $10 \%$ of the immigrants who leave the country do not fulfill this obligation in order to keep an option open for re-migration or access to better health care than in their country of origin $[1,35]$. In France, the proportion of missing deaths among Moroccan men was estimated at 23\% [10]. However, the SNC also includes deaths which had occurred abroad as covered by the foreigners' registration system, but not the routine mortality statistics. In the first period, this applies to 381 deaths ( $4 \%$ of deaths of firstgeneration and $1 \%$ of Switzerland-born Italians), in the second period to 933 ( $10 \%$ and $4.5 \%$, respectively).

A few methodical limitations should be mentioned. First, for the second period (after the 2000 census), information was missing for an unknown number of individuals having emigrated without notification and some deaths not linkable to the SNC. Restricting the analyses to the first period (1990-2000) may enhance reliability but at the expense of statistical power. Sensitivity analyses showed essentially the same patterns when limited to data from the first period. We, therefore, preferred to control the pooled analyses with a period dummy.
Second, we had no information on the exact origin of migrants. Since there is a substantial south-north gradient in mortality within Italy [36,37], analyses with this additional information may help explain differences in mortality between different migration groups. Third, the migration category 'Swiss nationals born in Italy' does not permit distinction between naturalized Italian immigrants and the offspring of Swiss nationals born in Italy. A fourth limitation is the lack of data on the duration of stay and on immigration class. The majority of Italians in Switzerland immigrated during the 1950s and 1960s. It is, therefore, possible that the observed differences between migration categories are confounded by cohort effects. However, immigration class should not bias our results.

\section{Conclusions}

We found significant differences in mortality between native Swiss and specific groups of individuals with Italian background in Switzerland. We observed substantial variation between first- and second-generation Italians: while first-generation males and females had a significant survival advantage compared to Swiss nationals, second-generation males demonstrated a significantly higher mortality risk. Given the substantial number of second-generation Italians, their poorer health might become a significant public health burden in the future. The situation of migrants and their offspring with respect to poorer self-reported and actual health status $[2,12,21,22,38]$ calls for public health actions focused on second-generation Italians. Further investigations should, therefore, take a closer look at potential resources (e.g., social networks, dietary patterns) and specific risks in health behavior, morbidity and cause-specific death rates, in order to customize preventive and health promotion efforts.

\section{Competing interests}

The authors declare that they have no competing interests.

\section{Authors' contributions}

MB conceived the study, prepared the data and contributed to the interpretation and writing of the manuscript. ST performed the analyses, contributed to the interpretation of the results, and wrote the first draft of the manuscript. Both authors read and approved the final version of the manuscript.

\section{Acknowledgements}

The authors are grateful to Julia Braun for statistical advice and to David Faeh and Jen Wang for helpful comments and proofreading.

The authors thank the Swiss Federal Statistical Office for providing mortality and census data and for the support which made the Swiss National Cohort and this study possible. The members of the Swiss National Cohort Study Group are Felix Gutzwiller (Chairman of Executive Board), Matthias Bopp (both Zurich), Matthias Egger (Chairman of Scientific Board), Adrian Spoerri, and Marcel Zwahlen (all Bern), Nino Künzli (Basel), Fred Paccaud (Lausanne) and Michel Oris (Geneva).

This work was supported by the Swiss National Science Foundation (grants 3347CO-108806 and 33CS30-134273). 
Received: 18 July 2012 Accepted: 17 December 2012

Published: 22 December 2012

\section{References}

1. Weitoft GR, Gullberg A, Hjern A, Rosén M: Mortality statistics in immigrant research: method for adjusting underestimation of mortality. Int J Epidemiol 1999, 28:756-763.

2. Bos V, Kunst AE, Keij-Deerenberg IM, Garssen J, Mackenbach JP: Ethnic inequalities in age- and cause-specific mortality in The Netherlands. Int J Epidemiol 2004, 33:1112-1119.

3. Deboosere $P$, Gadeyne $S$ : Adult migrant mortality advantage in Belgium: evidence using census and register data. Population - English edition 2005, 60:655-698

4. Singh GK, Hiatt RA: Trends and disparities in socioeconomic and behavioural characteristics, life expectancy, and cause-specific mortality of native-born and foreign-born populations in the United States, 1979-2003. Int J Epidemiol 2006, 35:903-919.

5. Singh GK, Siahpush M: All-cause and cause-specific mortality of immigrants and native born in the United States. Am J Public Health 2001, 91:392-399.

6. Adler NE, Boyce T, Chesney MA, Cohen S, Folkman S, Kahn RL, Syme SL: Socioeconomic status and health: the challenge of the gradient. Am Psychol 1994, 49:15-24.

7. Marmot MG, Shipley MJ, Rose G: Inequalities in death—specific explanations of a general pattern? Lancet 1984, 323:1003-1006.

8. Marmot MG, Smith GD, Stansfeld S, Patel C, North F, Head J, White I, Brunner E, Feeney A: Health inequalities among British civil servants: the Whitehall II study. Lancet 1991, 337:1387-1393.

9. Abraído-Lanza AF, Dohrenwend BP, Ng-Mak DS, Turner JB: The Latino mortality paradox: a test of the "salmon bias" and healthy migrant hypotheses. Am J Public Health 1999, 89:1543-1548.

10. Khlat $\mathrm{M}$, Darmon $\mathrm{N}$ : Is there a Mediterranean migrants mortality paradox in Europe? Int J Epidemiol 2003, 32:1115-1118.

11. Johansson LM, Sundquist J, Johansson SE, Bergman B, Qvist J, TräskmanBendz L: Suicide among foreign-born minorities and Native Swedes: an epidemiological follow-up study of a defined population. Soc Sci Med 1997, 44:181-187.

12. Sundquist $\mathrm{K}, \mathrm{Li} \mathrm{X}$ : Coronary heart disease risks in first- and secondgeneration immigrants in Sweden: a follow-up study. J Intern Med 2006, 259:418-427.

13. Abraído-Lanza AF, Armbrister AN, Flórez KR, Aguirre AN: Toward a theorydriven model of acculturation in public health research. Am J Public Health 2006, 96:1342-1346.

14. Carter-Pokras O, Bethune L: Defining and measuring acculturation: a systematic review of public health studies with hispanic populations in the united states. A commentary on Thomson and Hoffman-Goetz. Soc Sci Med 2009, 69:992-995.

15. Gushulak BD, MacPherson DW: The basic principles of migration health: population mobility and gaps in disease prevalence. Emerg Themes Epidemiol 2006, 3:3.

16. Gadd M, Johansson SE, Sundquist J, Wändell P: Are there differences in allcause and coronary heart disease mortality between immigrants in Sweden and in their country of birth? A follow-up study of total populations. BMC Public Health 2006, 6:102.

17. Marmot MG, Adelstein AM, Bulusu L: Immigrant mortality in England and Wales, 1970-78: Causes of death by country of birth. London: H.M.S.O; 1984.

18. Geddes M, Parkin DM, Khlat M, Balzi D, Buiatti E: Cancer in Italian migrant populations. Lyon: International Agency for Research on Cancer; 1993. IARC scientific publications, vol 123.

19. Swiss Federal Statistical Office: Statistisches Jahrbuch der Schweiz 1979. Basel: Birkhäuser Verlag; 1979.

20. Bilger V, Hollomey C, Wyssmüller C, Efionayi-Mäder D: Health Care for undocumented Migrants in Switzerland: Policies - People - Practices. Vienna: International Center for migration policy development; 2011.

21. Moreau-Gruet F, Luyet S: Migrationsbevölkerung und Gesundheit - Analyse der Hospitalisierungen. Neuchâtel: Swiss Health Observatory; 2012. Obsan-Bulletin, vol 1.

22. Bischoff $A$, Wanner PH: The self-reported health of immigrant groups in Switzerland. J Immigrant Minority Health 2008, 10:325-335.
23. Bopp M, Spoerri A, Zwahlen M, Gutzwiller F, Paccaud F, Braun-Fahrländer C, Rougemont A, Egger M: Cohort profile: the Swiss National Cohort-a longitudinal study of 6.8 million people. Int J Epidemiol 2008, 38:379-384.

24. United Nations Educational, Scientific and Cultural Organisation: International standard classification of education: ISCED 1997. Paris: Unesco; 1997.

25. Polasek W, Schuler M: Eidgenössische Volkszählung 1990. Bern: Swiss Federal Statistical Office; 1996.

26. StataCorp LP: stata11: Stata Statistical Software. College Station, TX: StataCorp.; 2009.

27. Wanner PH, Bouchardy C, Raymond L: Mortalité des étrangers en Suisse: Analyse par grand groupe des causes et par type de cancer 1989-1992. Neuchâtel: Swiss Federal Statistical Office; 2000.

28. Harding S, Balarajan R: Patterns of mortality in second generation Irish living in England and Wales: longitudinal study. BMJ 1996, 312:1389-1392.

29. Adelstein AM, Marmot MG, Dean G, Bradshaw JS: Comparison of mortality of Irish immigrants in England and Wales with that of Irish and British nationals. Ir Med J 1986, 79:185-189.

30. Singh GK, Miller BA: Health, life expectancy, and mortality patterns among immigrant populations in the United States. Can J Public Health 2004, 95:114-21.

31. Harding S: Mortality of migrants from the Indian subcontinent to England and Wales: effect of duration of residence. Epidemiology 2003, 14:287-292.

32. Harding S: Mortality of migrants from the Caribbean to England and Wales: effect of duration of residence. Int J Epidemiol 2004, 33:382-386.

33. Wessendorf S: Sushi-eating secondos and casual Latins: political movements and the emergence of a latino counter-culture among second-generation Italians in Switzerland.

J Intercult Stud 2007, 28:345-360.

34. Tubito M, King R: Italians in Peterborough: between integration, encapsulation and return. Falmer: Geography Laboratory, University of Sussex; 1996.

35. Westerling R, Rosén M: 'Avoidable' mortality among immigrants in Sweden. Eur J Public Health 2002, 12:279-286.

36. Fascioli S, Capocaccia R, Mariotti S: Cancer mortality in migrant populations within Italy. Int J Epidemiol 1995, 24:8-18.

37. Rasulo D, Spadea T, Onorati R, Costa G: The impact of migration in allcause mortality: the Turin longitudinal study, 1971-2005. Soc Sci Med 2012, 74:897-906.

38. Carballo M, Divino JJ, Zeric D: Migration and health in the European Union. Trop Med Int Health 1998, 3:936-944.

doi:10.1186/1471-2458-12-1104

Cite this article as: Tarnutzer and Bopp: Healthy migrants but unhealthy offspring? A retrospective cohort study among Italians in Switzerland. BMC Public Health 2012 12:1104.

\section{Submit your next manuscript to BioMed Central and take full advantage of:}

- Convenient online submission

- Thorough peer review

- No space constraints or color figure charges

- Immediate publication on acceptance

- Inclusion in PubMed, CAS, Scopus and Google Scholar

- Research which is freely available for redistribution 